\section{Storing 'Galia' Melons in a Controlled Atmosphere with Ethylene Absorbent}

\author{
Yair Aharoni', Azica Copel, and Elazar Fallik \\ Department of Fruit and Vegetable Storage, The Volcani Center, Agricultural \\ Research Organization, P.O. Box 6, Bet Dagan 50250, Israel
}

Additional index words. Cucumis melo pv. reticulates, storage life, shelf life, potassium permanganate

\begin{abstract}
The quality of 'Galia' melons (Cucumis melo pv. reticulates) stored in a controlled atmosphere (CA) of $10 \% \mathrm{CO}_{2}$ plus $10 \% \mathrm{O}_{2}$ with ethylene absorbent (EA) for 14 days at $6 \mathrm{C}$ and an additional 6 days at $20 \mathrm{C}$ was significantly better than that of control fruit or fruit stored in CA only. Fruit stored in CA plus EA were firmer and exhibited less decay than fruit from the other two treatments.
\end{abstract}

The 'Galia' melon is noted for its excellent flavor and aroma and is the primary melon grown in Israel for export and local market sale. The disadvantage of this delicate melon is its relatively short storage life. Due to its high rate of physiological aging, the melon softens after 2 to 3 weeks, even when maintained in low-temperature storage. Alternaria alternata (Fr.) Keissler and Fusarium spp. are the major causes of fungal rot in melon (Barkai-Golan, 1981). Coating the melon with

\footnotetext{
Received forpublication31 July 1992. Accepted for publication 11 Jan. 1993. Contribution from the The Volcani Center, Agricultural Research Organization, Bet Dagan, Israel, series E-3480, 1992. The cost of publishing this paper was defrayed in part by the payment of page charges. Under postal regulations, this paper therefore must he hereby marked advertisement solely to indicate this fact.

'To whom reprint requests should be addressed.
}

wax containing 1000 ppm (a.i.) allyl-1,2,4chlorophenyl-2-imidazol-1-ylethylether (imazalil) protects fruit from decay during storage at 6C (Temkin-Gorodeiski et al., 1983, 1985) but does not slow down their physiological aging and softening. Storing fruit at elevated $\mathrm{CO}_{2}$ and reduced $\mathrm{O}_{2}$ levels has reduced the physiological aging of fresh fruit and prolonged their storability and shelf life (Barkai-Golan, 1990). Stewart (1979) reported that storing cantaloupes in $20 \% \mathrm{CO}_{2}$ reduced decay and prolonged storage and shelf life. No data are available regarding the effect of a controlled atmosphere (CA) and an ethylene absorbent (EA) on 'Galia' melon storability and quality. Previous experiments with continuous flow-through storage systems indicated that $20 \% \mathrm{CO}_{2}$ was better than $5 \%$ or $10 \%$ in extending 'Galia' melon storability; however, this treatment impaired fruit flavor and aroma (Aharoni et al., 1990). A combination of $10 \% \mathrm{CO}_{2}$ and $10 \% \mathrm{O}_{2}$ extended the melon's storability without impairing its flavor and aroma (Aharoni et al., 1990).

The purpose of the present study was to determine if 'Galia' melons could be stored in $10 \% \mathrm{CO}_{2}$ and $10 \% \mathrm{O}_{2}$ on a semi-commercial scale. This involved storing the fruit in 700-liter air-tight plastic containers. Since the atmosphere in these containers was static, we also examined whether adding an EA influenced the quality of melons stored under these conditions.

'Galia' melons grown in the Arava region, the main melon-growing region in Israel, were harvested in Fall 1990 and Spring 1991. The fruit were treated in the packinghouse with Britex wax (Safepack, Raanana, Israel) containing 1000 ppm imazalil. Eight fruit were packed in each shipping carton. Eighteen cartons were placed in each of the two 700-liter plastic containers, while another 18 cartons were stored in the same storage room, but not inside a container, in normal atmosphere. In one container, each carton contained a 60mm-diameter, 40-mm-high plastic jar containing $30 \mathrm{~g}$ vermiculite soaked with saturated potassium permanganate (Scott et al., 1970). Carbon dioxide was introduced into the container from a pressurized cylinder until a concentration of $10 \%$ was reached. The $\mathrm{O}_{2}$ concentration was lowered to $10 \%$ by the $\mathrm{CO}_{2}$ and also by introducing $\mathrm{N}_{2}$. The containers (CA treatments) and the control fruit were maintained at $6 \mathrm{C}$ for 14 days. Carbon dioxide, $\mathrm{O}_{2}$ (both $\pm 0.5 \%$ ), and ethylene concentrations in the container were monitored twice a day by withdrawing 5-ml gas samples from the headspace with a syringe. Carbon dioxide and $\mathrm{O}_{2}$ were measured using a gas chromatography (GC) equipped with a thermal conductivity detector and a Poropak $\mathrm{N}$ column at $25 \mathrm{C}$. 
Helium was the carrier gas. Ethylene was measured using a GC equipped with aflame ionization detector and an alumina column at 80C. Nitrogen was the carrier gas. Excess $\mathrm{CO}_{2}$ was absorbed by soda lime, which was placed in a plastic bottle attached to the inner wall of the containers. When $\mathrm{O}_{2}$ concentration became $<10 \%$, a capillary was opened manually to allow the outside atmosphere into the container. The relative humidity $(\mathrm{RH})$ inside the containers was $\approx 96 \%$, while in the storage room it was $94 \%$. In both cases, RH was measured with a thermohygrograph (Casella, London). After 14 days of storage at $6 \mathrm{C}$, the containers were opened and all cartons were kept in air at 20C for 6 days to determine shelf life. The 14-day storage simulated the time required for sea freight to Europe, while the 6-day shelf life simulated market distribution and retailing.

Quality evaluations were conducted after 14 days of storage and 6 days after transfer to air at 20C. Firmness was measured (in Newtons) using a Chatillon penetrometer (John Chatillon and Sons, New York). Five fruit of each treatment were used each time. Each fruit was assessed on opposite sides along the equatorial region without removing the exocarp. Soluble solids concentration (SSC) was measured using the same fruit used to measure firmness. A segment of mesocarp tissue was removed and juice was dripped onto a digital refractometer (Atago Co., Tokyo) and measured at 20C. Total decay was expressed as the percentage of fruit that showed any decay. External appearance of the fruit was graded on a scale of 1 to 5 , with $1=$ poor (blemishes, decay, discoloration, and softness) and $5=$ excellent. Fruit rated higher than 2.5 were considered marketable. An informal flavor test was performed by eight panelists from our department after 6 days of shelf life. The experiments were repeated three times. Results were analyzed using Duncan's multiple range test at $P \leq 0.05$.

Daily gas monitoring in the CA container without EA showed a steady increase in ethylene concentration: $2.3,16.1$, and $27.2 \mathrm{ppm}$ were detected after 1 day, 1 week, and 2 weeks of storage, respectively. Ethylene in the CA container with EA remained at 0.2 to $0.3 \mathrm{ppm}$ relative to 0.05 to $0.2 \mathrm{ppm}$ of the normal atmosphere.

The external appearance of the fruit stored in CA with EA was significantly better after 14 days of storage plus an additional 6 days at 20C compared to those stored in CA and control treatments (Table 1). Fruit SSC remained $\approx 12.5 \%$ during storage. No differ-
Table 1. Quality of 'Galia' melons stored in a controlled atmosphere (CA) of $10 \% \mathrm{CO}_{2}$ and $10 \% \mathrm{O}_{2}$ (both $\pm 0.5 \%$ ) with and without ethylene absorbent (EA). Fruit were evaluated after 14 days in $\mathrm{CA}$ at $6 \mathrm{C}$ and after an additional 6 days at $20 \mathrm{C}$.

\begin{tabular}{|c|c|c|c|}
\hline Treatment & $\begin{array}{c}\text { Firmness } \\
(\mathrm{N})\end{array}$ & $\begin{array}{l}\text { Fruit } \\
\operatorname{rot}(\%)\end{array}$ & $\begin{array}{c}\text { External } \\
\text { appearance }\end{array}$ \\
\hline \multicolumn{4}{|c|}{ At harvest } \\
\hline Nontreated & 53 & 0.0 & 4.5 \\
\hline \multicolumn{4}{|c|}{ After 14 days in $C A$} \\
\hline Control & $49 \mathrm{a}^{y}$ & $5.6 \mathrm{a}$ & $3.5 \mathrm{~b}$ \\
\hline $\mathrm{CA}$ & $49 \mathrm{a}$ & $2.1 \mathrm{~b}$ & $4.0 \mathrm{a}$ \\
\hline $\mathrm{CA}+\mathrm{EA}$ & $50 \mathrm{a}$ & $1.4 \mathrm{c}$ & $4.0 \mathrm{a}$ \\
\hline \multicolumn{4}{|c|}{ After an additional 6 days at $20 \mathrm{C}$} \\
\hline Control & $32 \mathrm{c}$ & $16.0 \mathrm{a}$ & $2.0 \mathrm{c}$ \\
\hline $\mathrm{CA}$ & $36 \mathrm{~b}$ & $6.4 \mathrm{~b}$ & $3.0 \mathrm{~h}$ \\
\hline $\mathrm{CA}+\mathrm{EA}$ & $39 a$ & $4.8 \mathrm{c}$ & $3.5 \mathrm{a}$ \\
\hline
\end{tabular}

${ }^{2}$ External appearance: 5 = excellent, $1=$ poor.

yean separation within each examination by Duncan's multiple range test, $P \leq 0.05$.

ences in flavor were noticed among the fruit stored under the various conditions (data not shown).

Melon firmness decreased during storage and shelf life. During 14 days of storage, the firmness of control fruit decreased by $4 \mathrm{~N}$, but was not significantly different from the CA treatments (Table 1). However, after 6 days in normal atmosphere at $20 \mathrm{C}$, fruit previously stored in CA were significantly firmer than control fruit. Fruit stored in CA with EA were firmer than those stored in CA without EA (Table 1).

Rot developed during the initial 14-day storage period (Table 1); however, after an additional 6 days of storage at normal atmosphere, the incidence of decay in the control fruit was 2.5 times that in fruit stored in CA and only 3.3 times that in fruit stored in CA plus EA. Alternaria alternata and Fusarium spp. were the main infectious agents that developed on the melons during storage and shelf life.

The data obtained in our study indicate that there is an advantage to storing 'Galia' melons in an atmosphere of $10 \% \mathrm{CO}_{2}$ and $10 \% \mathrm{O}_{2}$. This atmosphere slowed fruit softening and reduced decay incidence. Removing ethylene from the CA-storage atmosphere further slowed melon aging and deterioration. Similar results have been reported for other fruit, including 'McIntosh' apples (Malus domestica Borkh.) (Liu and Samuelson, 1986) and 'Lula' avocados (Persea americana Mill.) (Hatton and Reeder, 1972). CA storage with EA also reduced mold incidence in lemons [Citrus limon (L.) Bum.] (Wild et al., 1976).
SSC concentration did not change markedly during storage and shelf life. Similar results were found for other melon cultivars stored for 9 days at 5 or $12.5 \mathrm{C}$ (Cohen and Hicks, 1986). The fact that CA plus EA prolonged the storage and shelf life of 'Galia' melons without undesirable effects on flavor and other quality attributes raises the possibility of using long-distance sea freight in CA containers for transporting melons.

\section{Literature Cited}

Aharoni, Y., R. Barkai-Golan, N. TamkinGorodeiski, A. Copel, and H. Davidson. 1990. Prolonging the storage life of 'Galia' melons for export (in Hebrew). Rpt. Dept. of Fruit and Veg. Storage, Agr. Res. Organization, The Volcani Center, Bet-Dagan, Israel.

Barkai-Golan, R. 1981. An annotated check-list of fungi causing postharvest diseases of fruits and vegetables in Israel. Agr. Res. Organization, The Volcani Center, Bet-Dagan, Israel. Special Publ. 194.

Barkai-Golan, R. 1990. Postharvest disease suppression by atmospheric modifications, p. 238264. In: M. Calderon and R. Barkai-Golan (eds.). Food preservation by modified atmospheres. CRC Press, Boca Raton, Fla.

Cohen, R.A. and J.R. Hicks. 1986. Effect of storage on quality and sugars in muskmelon. J. Amer. Soc. Hort. Sci. 114:553-557.

Hatton, T.T. and W.F. Reeder. 1972. Quality of 'Lula' avocados stored in controlled atmosphere with or without ethylene. J. Amer. Soc. Hort. Sci. 97:339-341.

Liu, F.W. and D. Samuelson. 1986. Rates of change in firmness, acidity, and ethylene production of 'McIntosh' apples in simulated low-ethylene CA storage. J. Amer. Soc. Hort. Sci. 111:404408.

Scott, K.J., W.B. McGlasson, and E.A. Roberts. 1970. Potassium permanganate as an ethylene absorbent in polyethylene bags to delay ripening of banana during storage. Austral. J. Expt. Agr. Animal Husbandry 10:237-240.

Stewart, J.K. 1979. Decay of muskmelons stored in controlled atmosphere. Scientia Hort. 11:69-74.

Temkin-Gorodeiski, N., U. Zissman, S. Grinberg, and A. Daos. 1983. Prevention of decay in 'Galia' melons designed for export (in Hebrew). Rpt. Dept. of Fruit and Veg. Storage, Agr. Res. Organization, The Volcani Center, Bet-Dagan, Israel.

Temkin-Gorodeiski, N., S. Grinberg, and G. Gur. 1985. Testing new disinfecting substances for decay control in 'Galia' melons during storage (in Hebrew). Rpt. Dept. of Fruit and Veg. Storage, Agr. Res. Organization, The Volcani Center, Bet-Dagan, Israel.

Wild, B.L., W.B. McGlasson, and T.H. Lee. 1976. Effect of reduced ethylene levels in storage atmosphere on lemon keeping quality. HortScience 11:114-115. 